\title{
A arquitetura da informação organizacional e os modelos que gerenciam competências.
}

José Juan Espantoso

Resumo: Apresenta considerações sobre a arquitetura da informação organizacional e sobre o gerenciamento de conjuntos de competências em espaços de informações digitais. São discutidas a gestão de competências e sua importância para o trabalho dos profissionais que atuam nesses ambientes.

Palavras-chave: Arquitetura da Informação Organizacional; Competências; Gestão de Competências; Profissional da Informação; Arquiteto da Informação.

Abstract: Presents considerations about organizational information architecture and about the management of competences groups in digital information spaces environment. Discuss competences management and the importance to the information professionals.

Key Words: Competences; Competence Management, Information Architect, Information Professional, Organizational Information Architecture.

15 Resumen: Presenta consideraciones sobre la arquitectura de la información organizacional y sobre la administración de conjuntos de competencias en espacios de informaciones digitales. Es discutido la gestión de las competencias y su importancia para el trabajo de los profesionales que actúan en esos ambientes.

Palabras Claves: Arquitectura de la Información Organizacional; Habilidades; Gestión de la Información; Profesionales de la Informació; Arquitecto de la Información. 


\section{Introdução}

O crescimento exponencial do volume de informação armazenada observado em repositórios informacionais das organizações é ocasionado em grande parte, pela redução de custos de estocagem e conservação e pelo surgimento de novas mídias e demais suportes de armazenamento. A facilidade no acesso à informação cresce na medida em que aumenta o número de pessoas que utilizam recursos de tecnologia da informação.

Os avanços desencadeados pela ampliação dos acessos aos conteúdos e pelo fenômeno da conectividade facultam com que consultas a repositórios de informação sejam realizadas em pontos distantes do planeta. Muitas vezes, estas são elaboradas por intermédio de transações simultâneas, aumentando a complexidade das operações.

A inovação, mola mestre da Sociedade da Informação fornece a componente dinâmica ao processo de gerenciamento da informação, "seduzindo" e incentivando mais usuários a participarem de ambientes, em que são disponibilizadas modernas ferramentas e práticas para o acesso a informação.

A transformação social que a informação produz pode ser evidenciada no surgimento de novos postos de trabalho, apresentando-se assim, como um fenômeno em que emergem inúmeras novas profissões, transformando e diversificando a natureza cultural e institucional da Sociedade da Informação.

A arquitetura da informação pode ser caracterizada como um esforço para a unificação de métodos relacionados com a recuperação, classificação, organização e apresentação da informação, que, em grande parte, são temas estudados nas áreas de Biblioteconomia e Ciência da Informação e emprega técnicas originárias da arquitetura aplicadas a ambientes digitais, (CAMARGO; VIDOTTI, 2006, p. 106).

Os espaços informacionais das organizações estão cada vez mais complexos, influenciados pelo surgimento de novas soluções de tecnologia da informação e por técnicas e metodologias de diversos campos do saber. Para o gerenciamento de tais espaços as organizações necessitam de profissionais altamente capacitados.

As organizações buscam, desta forma, planejar ações com eficiência minimizando, quando possível, despesas e, que ainda sim permitam o emprego racional de seus recursos humanos a fim de não comprometer os níveis de qualidade dos processos organizacionais. Nestes esforços, são amplamente discutidos postos de trabalho, aquisição de competências e planos de carreira. 
Assim, a gestão de competências pode ser estudada com o auxílio de modelos que evidenciem tanto atributos organizacionais quanto individuais necessários para o sucesso de uma empresa. Estes contemplam os diversos níveis de uma organização auxiliando no gerenciamento de conjuntos de competências e na avaliação de práticas de gestão de recursos humanos.

\section{A arquitetura da informação}

Já se passou um bom tempo desde que o bibliotecário Callimachus catalogou, organizou e recuperou informações na famosa Biblioteca de Alexandria (três séculos antes de Cristo), fato que provavelmente inspirou Melvil Dewey no ano de 1870 a criar o Sistema Decimal. Muito tempo depois, Richard Saul Wurman ', precisamente em 1975, cunhou os termos arquiteto da informação e arquitetura da informação.

Sobre as origens da arquitetura da informação, Morville (2005, p. 7-9) destaca a existência de uma dificuldade na caracterização de seu surgimento. Na visão do autor os princípios da arquitetura da informação são aplicados há décadas. O autor ainda enaltece a necessidade de que o arquiteto da informação conheça questões referentes a necessidades de informação, hábitos, comportamentos e experiências dos usuários.

Segundo informação publicada no portal da ASIS\&T ii a arquitetura da informação é caracterizada como um conjunto de atividades estruturadas e padronizadas que provê acesso a informações com o objetivo de organizar e disponibilizar conteúdos, facilitando a navegação e a recuperação. Esta associação possui diversos grupos de interesse caracterizados como SIGs (Special Interest Group) iii onde fluem intensos debates que colaboram para a consolidação de conceitos em diversas áreas, entre elas pode-se destacar o tema relativo a arquitetura da informação,

A busca por definições e áreas de atuação a respeito da arquitetura da informação tem inspirado muitos autores como pode-se ser destacado no texto a seguir:

Para se tornar eficaz, a arquitetura da informação deverá atuar como uma instância mediadora entre os interesses dos usuários, do cliente, do time gráfico e da equipe de programação. No centro de uma complexa rede de idéias diferentes e de pontos de vista divergentes, o arquiteto de informação emprega um arsenal de técnicas combinadas à sua capacidade de comunicação interpessoal - para traduzir as necessidades e os objetivos dos usuários aos demais. (AGNER, 2006, p. 88) 
No ano de 1998, Luis Rosenfeld e Peter Morville apresentaram a primeira edição do livro Information Architecture for the World Wide Web ${ }^{i v}$. Em 2002, a segunda foi publicada, ocorrendo o lançamento da terceira edição no ano de 2006. Esta obra que define como principais atividades do tema a apresentação, organização e navegação da informação está auxiliando na consolidação de conceitos referentes a arquitetura da informação no ambiente web e em pouco tempo tornando-se umas das principais obras de referência sobre o assunto.

A apresentação da informação é o elo mais externo em um processo de comunicação. Rótulos podem ser empregados para representar conteúdos em espaços de informação, e assim, minimizar os esforços despendidos nas ações de recuperar informação. É uma maneira de viabilizar um processo comunicacional, da mesma forma que palavras são utilizadas para expressar idéias, também rótulos, legendas ícones, gráficos, etc. podem representar os acessos a grandes volumes de informação em ambientes digitais, (PEÓN ESPANTOSO, 2001, p. 14).

Caraballo Pérez; Ramírez Céspedes (2007, p. 31) esclarecem que a organização da informação no ambiente web atinge graus de complexidade superiores comparado a outros contextos. No ciclo de vida da informação esta tarefa é composta por etapas como: seleção, processamento e armazenamento.

Segundo Lopes (2004, p. 60) os sistemas de recuperação da informação agregam complexidade às atividades de armazenamento e busca da informação, pois envolvem aspectos relacionados ao emprego de recursos de $\mathrm{TI}^{\mathrm{v}}$, e possuem como objetivo viabilizar acessos realizados em regiões geograficamente dispersas.

A dificuldade em se recuperar informação é exaltada por Wurman (2001, p. 176) em sua obra Ansiedade da Informação. O autor destaca que a todo o momento em que informações são processadas, outras são requeridas, evidenciando um ciclo virtuoso. $\mathrm{O}$ desafio é tornar disponível de forma tempestiva e consistente os conteúdos requeridos, e desta forma, compelir usuários a interagir com novos espaços informacionais.

\section{0 arquiteto da informação}

Um arquiteto, de maneira geral, é um profissional que planeja, projeta e supervisiona a construção de diferentes tipos de estruturas. O arquiteto, desta maneira, está envolvido em todas as fases do desenvolvimento de um projeto, desde discussões iniciais com os clientes até as etapas de construção e implantação. As atividades dos arquitetos são complexas, pois em suas atribuições fazem parte o entendimento de métodos de construção, princípios gerais de engenharia e o emprego de ferramentas para diversos fins, (CAREER DIRECTIONS, 2005). 
Garrett (2002) vi caracteriza o arquiteto da informação como um profissional que atua em atividades relacionadas a organização de conteúdos e a estruturação de espaços informacionais. A experiência e bagagem que muitos arquitetos da informação trazem, frutos da realização de tarefas em outras áreas são úteis em suas novas atividades.

Cunha; Cavalcante $(2008$, p. 23 ) apresentam os termos arquiteto da informação como ocupação que despontou de fato no início do presente século, conforme pode ser observado na definição abaixo:

\begin{abstract}
Uma nova denominação, surgida no início do século XXI, para o profissional da informação. Ele, geralmente, tem por funções: organizar os padrões inerentes aos dados ou informações; e criar a estrutura ou mapa da informação, com o objetivo de permitir que as pessoas encontrem seus caminhos pessoais para o conhecimento. 2 INF INTERN especialista responsável pela produção de um protótipo de sitio Web, inclusive a estruturação e organização da informação, a organização dos conteúdos e a definição das interfaces de acesso e busca.
\end{abstract}

Morrogh (2002, p. 131) destaca que os arquitetos da informação são considerados profissionais da informação emergentes. Na percepção do autor, muitos são os praticantes da arquitetura da informação engajados em um processo de identificação e definição de "[...] um único e singular conjunto de habilidades e conhecimentos [...]" para o estabelecimento da profissão. Estes, que muitas vezes foram capacitados em outras áreas, participam de forma atuante em conferências e congressos com o firme propósito de buscar o reconhecimento profissional para a categoria. Uma das primeiras organizações patrocinadoras destes eventos foi a American Society for Information Science and Technology (ASIS\&T) ${ }^{\text {vii. }}$.

A visibilidade do trabalho do arquiteto da informação é percebida pelos usuários na interação, que este realiza, com as interfaces elaboradas. Como caracterizado na fig. 1, para que o processo de mediação seja eficiente, um exaustivo trabalho deve ser efetuado que leva em consideração esquemas, meta dados, tesauros, etc. 


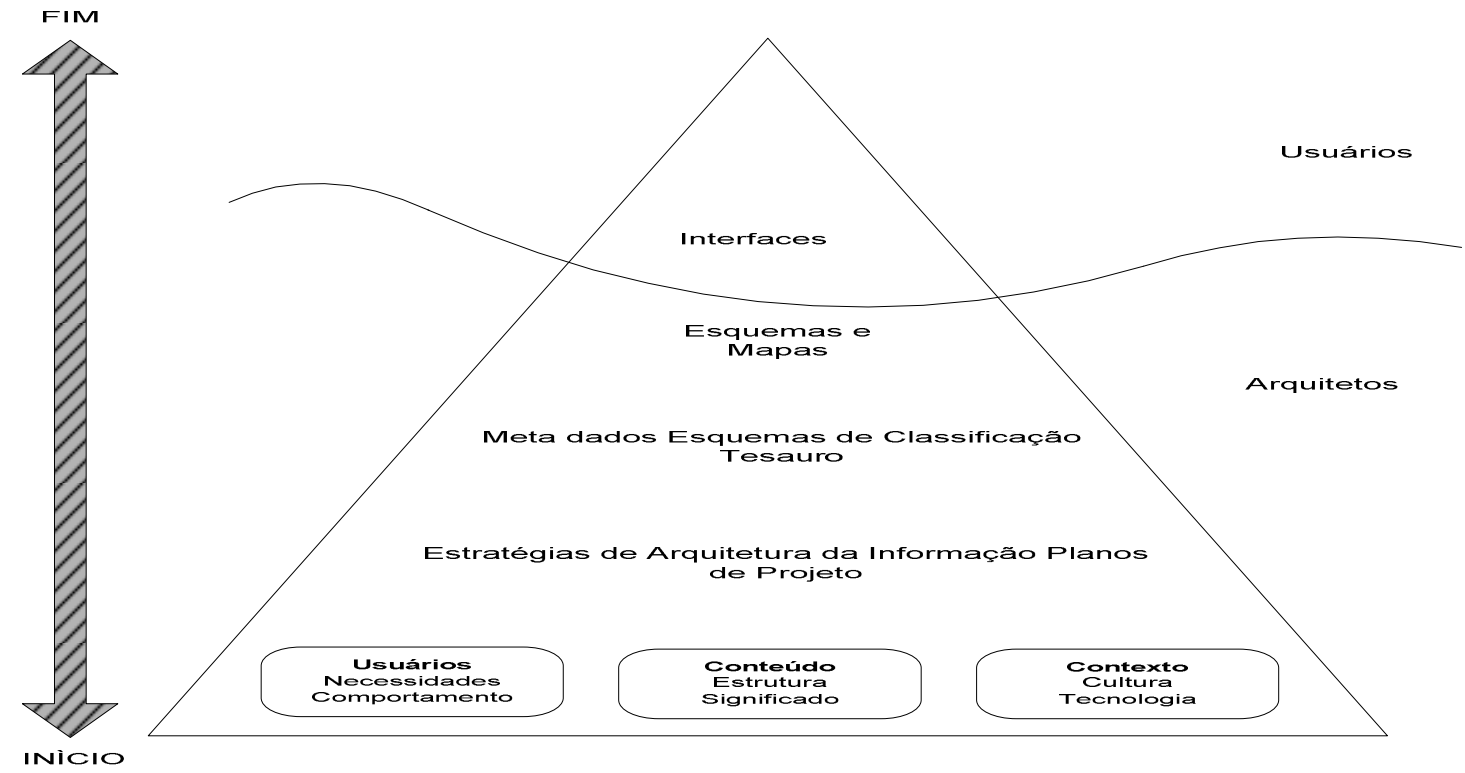

Figura 1 - Visibilidade sob a Perspectiva do Usuário e o Trabalho do Arquiteto da Informação (Fonte: Velasco Martín, 2005, p. 15)

Sobre arquiteto da informação Guenther $(2005$, p. 3) acrescenta que esta é uma das mais interessantes ocupações surgidas que pouco a pouco adquire prestígio e reconhecimento em ambientes de desenvolvimento e gerenciamento da informação de grandes organizações.

Assim, este novo profissional da informação está contribuindo para a fundação de um campo do saber que tem como preocupações básicas a organização, a recuperação e a apresentação da informação. Arquitetos da informação possuem habilidades e competências para a elaboração de tarefas em diversos espaços informacionais, permitindo com que complexos conteúdos sejam acessíveis e compreensíveis pelos usuários.

\section{A arquitetura da informação organizacional}

A aplicação da arquitetura da informação em ambiente organizacional é descrita por Dave apud Cunha; Cavalcanti (2008, p. 23, op cit.) como sendo:

Mapa do ambiente informacional de uma organização, apenas no seu presente, podendo oferecer um modelo de ambiente a ser seguido no futuro. Ela faz a ponte entre o comportamento, os processos e o pessoal especializado e outros aspectos da empresa, como métodos administrativos, estrutura organizacional e espaço físico. 
Casagrande (2005, p. 82) afirma que diversas organizações aplicam rotineiramente conceitos relacionados à arquitetura da informação, aliando o uso de métodos e técnicas na integração de sistemas de informação organizacionais, com o objetivo de administrar de forma eficiente recursos alocados e disponibilizados para o gerenciamento de espaços informacionais.

A arquitetura da informação no contexto organizacional é definida por Abell; Wingar (2005) como um conjunto coerente de estratégias e planos que propiciam acesso eficiente e seguro aos conteúdos. Os autores explicam que o termo pode parecer eminentemente técnico e, desta maneira, confinado ao uso em contextos específicos, mas que na realidade adquire ampla aplicabilidade, pois evidencia resultados e esforços de muitos profissionais da informação, como apresentado na fig. 2:

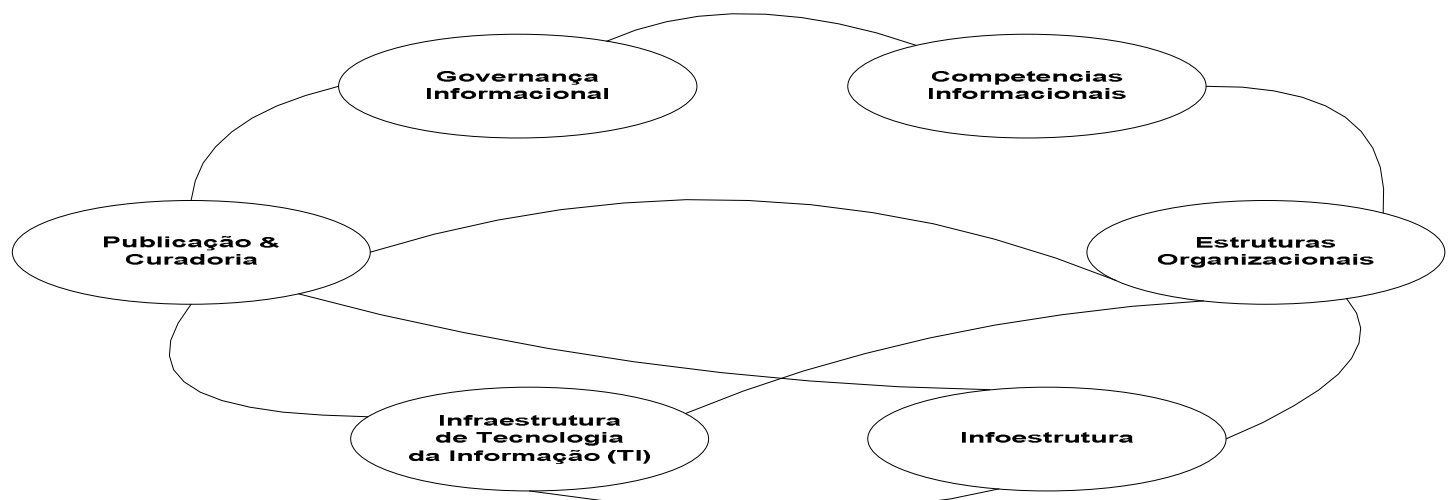

Figura 1 - Os Componentes da Arquitetura da Informação em Ambiente Organizacional

(Fonte: Abell; Wingar, 2005)

O trabalho do profissional que trabalha com a arquitetura da informação é viabilizado pela presença de uma infra-estrutura de artefatos de $\mathrm{TI}$, responsável por viabilizar, entre outros, mecanismos para o armazenamento da informação, motores de busca e dispositivos de segurança. A infoestrutura está relacionada com meta dados, estratégias de classificações e políticas para padronizações, e assim, abrange várias etapas do ciclo informacional (aquisição, classificação, armazenamento, disseminação e preservação).

Os impactos que a infra-estrutura em TI está realizando nos modelos estudados permitem com que novos frameworks viii em arquitetura da informação sejam desenvolvidos. Desta forma, quando investigada no meio organizacional a arquitetura da informação adquire complexidade e importância.

A aplicação de políticas organizacionais permite a difusão criteriosa de informações entre membros de uma instituição e entre instituições por intermédio do emprego de 
parâmetros de segurança que respeitem as regras de confiabilidade de uma organização. Assim, tecnologias, padrões de projeto e políticas organizacionais estão entre os pilares do emprego eficiente da arquitetura da informação organizacional.

\section{As competências do arquiteto da informação}

Como foi visto, as atividades e competências do arquiteto da informação estão relacionadas com a realização de tarefas relativas ao gerenciamento de espaços digitais. 0 esforço em identificar, caracterizar e relacionar suas competências é complexo, pois envolve estudos que combinem conceitos em diversos campos do saber. Desta forma, o arquiteto da informação desempenha funções e tarefas que aplicam conceitos da: Ciência da Informação, Comunicação e Ciência da Computação.

O trabalho do arquiteto da informação tem seu início em um amplo e minucioso levantamento de requisitos, onde são identificadas as necessidades de informação. Esta tarefa é dividida em quatro etapas de levantamento de requisitos: negócio, usuários, projeto e técnicos. Os resultados alcançados auxiliam no desenvolvimento de ambientes sintonizados com os objetivos da organização e com os anseios das audiências, (HENDERSON; WILSON; SHIMBO, 2006, p. 1022-1023).

Para Sánchez Bustamante (2004, p. 3) um arquiteto da informação deve reunir conhecimentos de diversas áreas, entre elas o autor destaca:

a) projeto gráfico - refere-se à habilidade de estabelecer relações entre elementos visuais que determinam uma harmoniosa integração de cada componente;

b) documentação e informação - baseia-se no estudo e criação de meios para o acesso à informação e no estabelecimento de formas apropriadas de organização que permitam uma eficiente recuperação;

c) comunicação - leva em consideração, entre outros aspectos, as diferenças de estilos de redação em ambientes virtuais;

d) marketing - reúne informações de mercados e realiza estudos sobre usuários;

e) ciência da computação - estuda aplicações de TI;

f) engenharia da usabilidade - reúne métodos para avaliação de funcionalidades, desde a curva de aprendizagem até as inconsistências mais freqüentes apresentadas em interfaces desenvolvidas para a interação com usuários. 
Sobre competências dos arquitetos da informação foi conduzida pelo IAlnstitute ${ }^{\mathrm{ix}} \mathrm{em}$ 2004 pesquisa que levantou dados de 166 profissionais. As competências mais citadas estão explicitadas na fig. 3 :

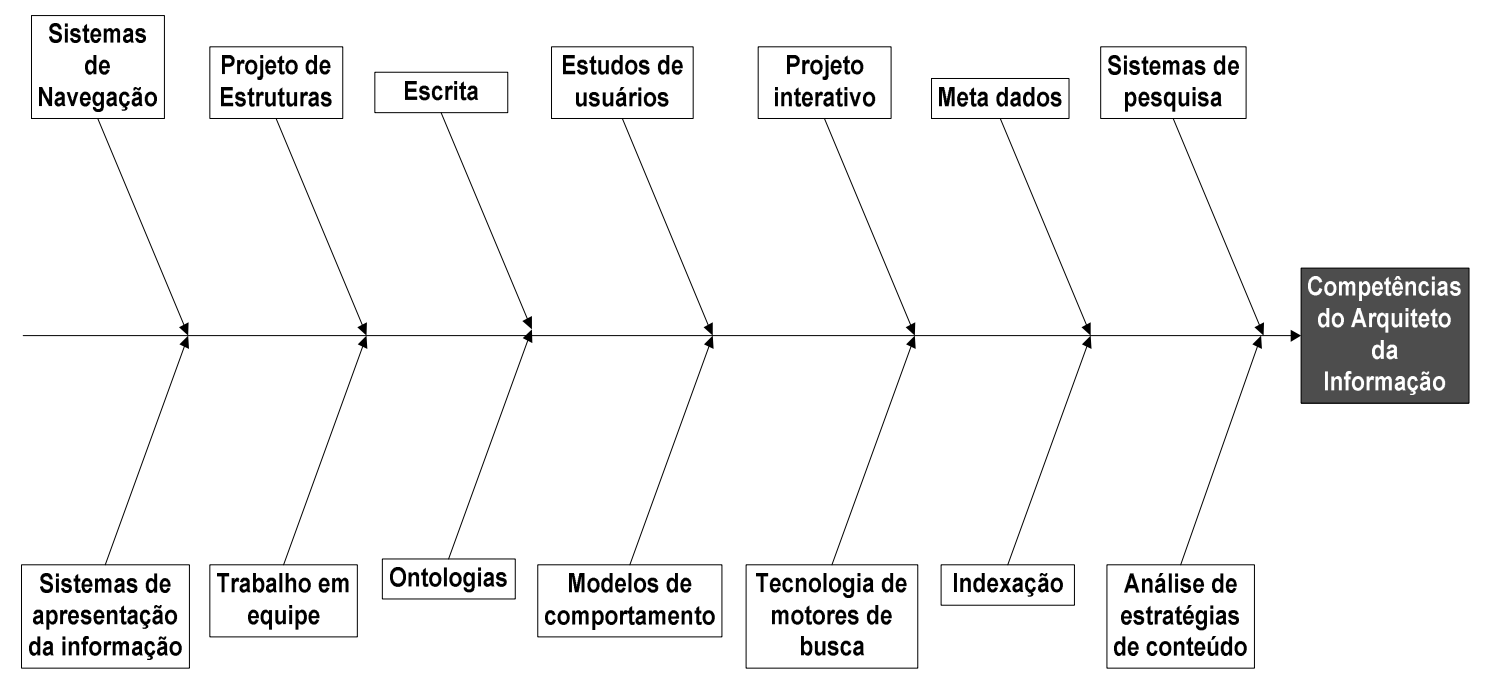

Figura 3 - Competências do Arquiteto da Informação

(Fonte: IAlnstitute, 2004, com adaptações)

Das competências informacionais apresentadas, sistemas de apresentação da informação e projeto interativo referem-se ao conceito da arquitetura da informação responsável pela confecção de interfaces. Sistemas de navegação, projeto de estruturas e sistemas de pesquisa concernem a recuperação da informação. Meta dados, ontologias, aplicação de tecnologias referentes a motores de busca, indexação e análises de conteúdos abrangem a organização da informação. É interessante frisar que duas competências pessoais do arquiteto da informação surgiram na pesquisa (escrita e capacidade de trabalhar em equipes).

O mapa de escala multidimensional de competências dos arquitetos da informação, fruto de pesquisa realizada com profissionais da área pelo Information Architecture Institute ${ }^{\times}$ realizada em 2007, apresenta três dimensões. O tamanho do círculo que representa cada competência indica a relevância e o número de entradas detectadas na investigação. Para a elaboração do gráfico síntese os pesquisadores levaram em consideração similitudes evidenciadas nas áreas de gerenciamento de conteúdos, estudos de usuários, aplicação de tecnologias e elaboração de projetos. As competências identificadas na cor rosa podem ser obtidas em disciplinas oferecidas nos cursos de Biblioteconomia e Ciência da Informação, sendo que algumas delas são definidas como centrais para a arquitetura da informação como apresentação, organização e recuperação da informação. As competências compreendidas 
pela cor azul especificam todas aquelas que podem ser obtidas em cursos relacionados com a Ciência da Computação e com as Engenharias. Estas evidenciam algumas competências pessoais, tais como: técnicas de apresentação e colaboração no trabalho em equipes. A terceira dimensão assinalada no gráfico particulariza competências que podem ser granjeadas em cursos abrangidos por áreas como: Ciências Humanas e Ciências Sociais.

O produto do trabalho do arquiteto da informação, desta forma, reflete um amplo esforço realizado no levantamento de requisitos, estudos e comportamentos de usuários, no gerenciamento de conteúdos (tanto no que se refere à estruturação quanto à organização) e no contexto (cultura organizacional, recursos disponibilizados em TI, políticas, etc.).

As experiências obtidas pelo profissional da informação na construção de soluções em arquitetura da informação propiciam com que novos projetos sejam realizados em ambientes ou organizações similares, permitindo a elaboração de templates ${ }^{x i}$ e assim edificando arcabouço com teorias e práticas que auxiliarão o desenvolvimento da área.

\section{A gestão de competências em ambientes de arquitetura da informação organizacional}

De acordo com Gil (2001, p. 47), muitas organizações tiveram dificuldades para se adaptarem a ambientes em constantes mudanças, algumas foram obrigadas a vivenciar novas realidades como, por exemplo, terceirizações, elaboração de reengenharias e implantações de modelos de qualidade, que impactaram enormemente no gerenciamento e administração de recursos humanos.

O amadurecimento das relações indivíduo-empresa necessárias para as novas demandas dos mercados de trabalho faz surgir, conforme enaltecido por Trasatti; Costa (2005, p. 13-21), mudanças nos ambientes organizacionais. Os autores propõem modelo de gestão de competências que evidencia os esforços das organizações no sentido de levantar estratégias, e necessidades de mercado, assim como identificar recursos, conforme apresentado na fig. 4: 


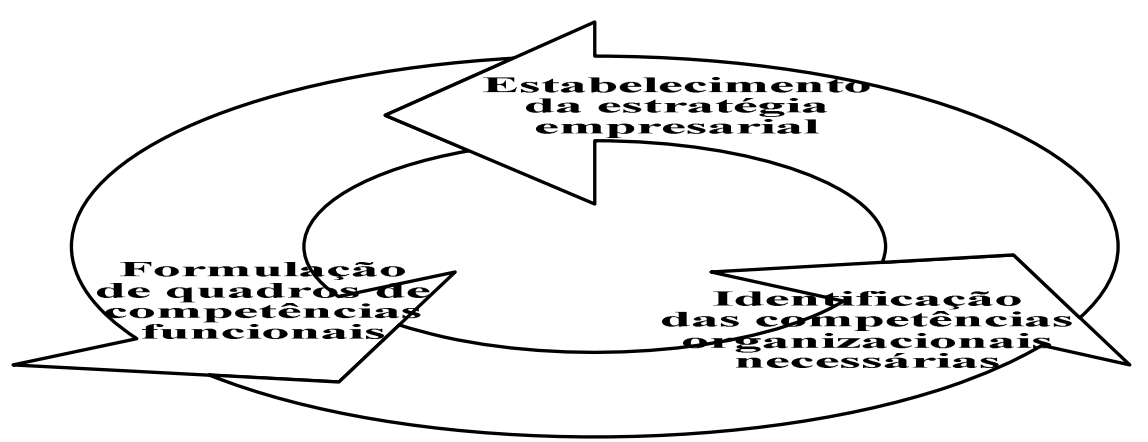

Figura 4 - Ciclo das Competências

(Fonte: Trasatti; Costa, 2005, p. 19)

O ciclo de competências apresenta uma componente dinâmica que sofre, segundo os autores (ibidem), revisões freqüentes, permitindo com que novas habilidades, atitudes e comportamentos possam ser agregados ao processo. Quando este se torna estável surge uma linguagem de desempenho, esta estabelece relações entre necessidades e existências, fornecendo subsídios indispensáveis à elaboração de estratégias que auxiliem na busca por soluções compatíveis com os anseios e aspirações das organizações.

Ramos (2001, p. 80-81) apresenta como solução para a dificuldade em se estudar e implantar modelos que expressem ciclos de competências, uma estrutura com três subsistemas que consiste em: mecanismos para a retenção de competências, processos e certificações que cataloguem e normalizem competências existentes e rotinas que avaliem a necessidade de obtenção de novas competências.

Um modelo de competência é normalmente uma descrição narrativa de competências ocupacionais para um grupo identificável, como uma categoria ocupacional, um departamento ou uma ocupação. Ele distingue performances exemplares (best-in-class ${ }^{x i i}$ ) de outras performances. (ROTHWELL; LINDHOLM, 1999, p. 91, tradução nossa)

Existem maneiras distintas de gerenciar competências em ambientes de arquiteturas da informação organizacionais, todas manifestam o objetivo de empregar com eficiência recursos humanos. Berbaum, (1982, p. 56) propõe modelo que parte da realidade de uma organização em termos de recursos humanos, agregando novas competências fruto da observação interna ou de experiências vivenciadas em outras corporações similares. 
Dentro desta perspectiva, Ruas (2005, p. 34-37) enaltece a importância do emprego de modelos a respeito de ciclos de competência e seus impactos no gerenciamento da informação nas organizações. Estes, segundo o autor, propiciam a aproximação dos interesses das dimensões organizacional e pessoal, alcançando resultados e produtividade em ambientes de profundas transformações.

A implantação da gestão de competências deve contemplar todos os níveis de uma organização, provocando assim significativos impactos no gerenciamento das informações, o que é enaltecido na proposta apresentada por Guimarães et al. (2001, p. 250).

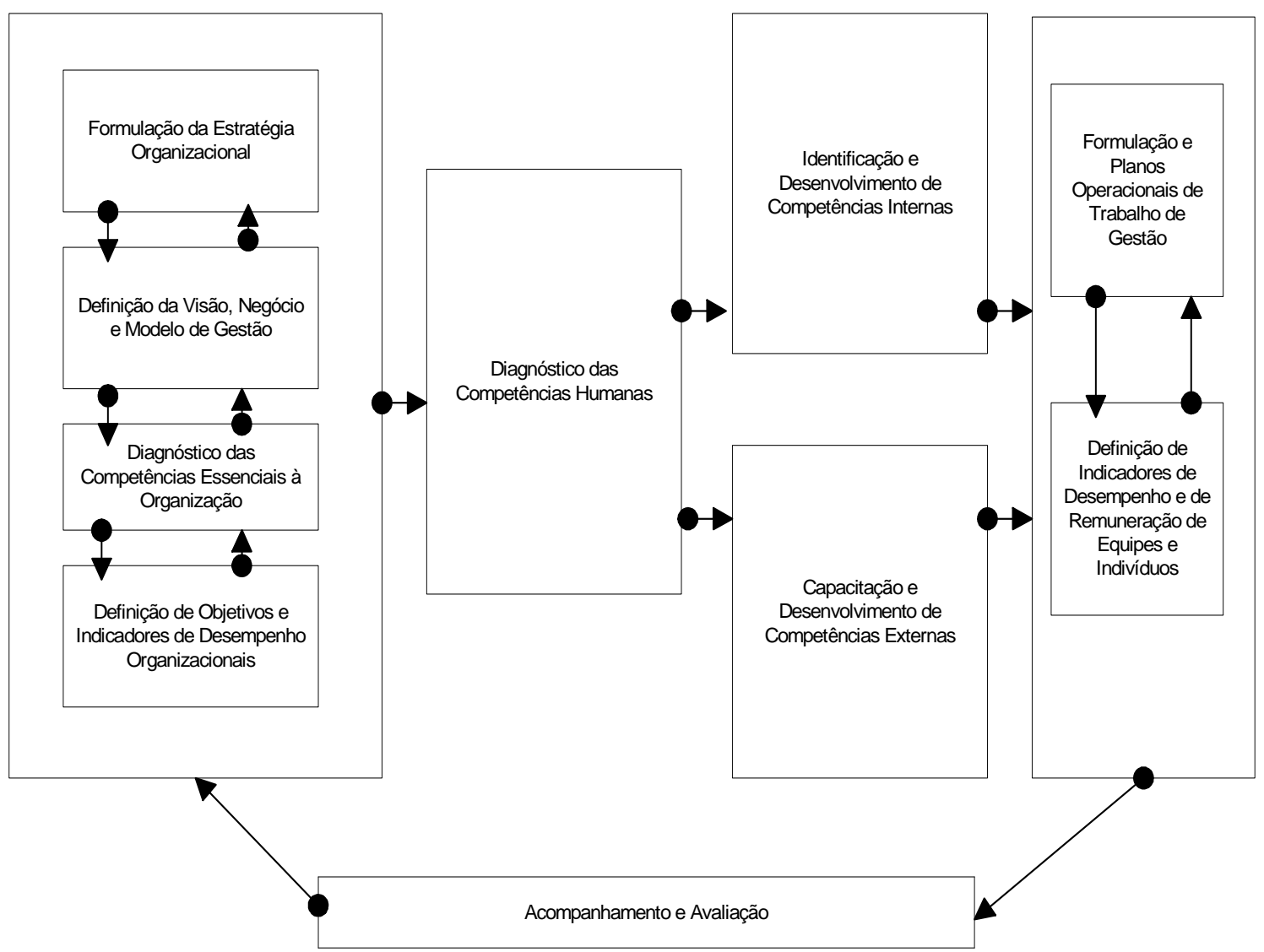

Figura 2 - Processo de Gestão de Desempenho Baseado nas Competências

(Fonte: Guimarães et al., 2001, p. 250)

No processo de gestão de desempenho os autores enaltecem que a estratégia organizacional deve estar em consonância com o negócio e o modelo de gestão de recursos humanos, e assim, permitir a definição de competências necessárias e indicadores de desempenho que norteiam a capacitação e o desenvolvimento dos quadros.

Brandão; Bahry (2005, p. 181) apresentam modelo de gestão de competências, em que questões centrais na formulação de estratégias organizacionais tais como: missão, visão e 
objetivos estratégicos instituem as metas de desempenho que servirão de subsídio para o diagnóstico situacional. Assim, identificando necessidades e inventariando competências existentes é possível levantar demandas ainda não contempladas, fundamentais para o planejamento e para o processo de captação de novos recursos.

A arquitetura da informação organizacional, desta forma, aplicada em ambientes onde existem práticas de gestão de competências pode ser beneficiada. A exploração eficiente de recursos em termos de competências permite com que projetos de arquitetura sejam mais bem elaborados, e como conseqüência um melhor gerenciamento dos espaços informacionais.

\section{Considerações finais}

A arquitetura da informação é caracterizada por um conjunto de atividades interrelacionadas com a finalidade de prover de forma organizada o acesso a informação. A interdisciplinaridade dos campos de atuação da disciplina está se tornando um dos grandes desafios para gestores e administradores de recursos humanos, principalmente no que diz respeito ao gerenciamento dos espaços de informação.

O estabelecimento, a caracterização da atuação e a identificação de competências dos profissionais da informação é uma meta complexa, na medida em que estes integram equipes multidisciplinares para a gestão da informação e do conhecimento. Nestes quadros é fundamental que a formação, a experiência e os conhecimentos se complementem e sejam convergentes com as atividades que a serem realizadas.

As competências relativas ao profissional arquiteto da informação o habilitam para complexas tarefas relacionadas ao gerenciamento de espaços de informação. O esforço em identificar, caracterizar e relacionar suas competências é essencial, pois em suas composições estão conceitos de diversos campos do saber que quando estudadas em ambientes organizacionais apresentam significado especial.

No trabalho realizado em um projeto de arquitetura da informação organizacional podem ser destacadas as atividades de publicação de atos institucionais e o gerenciamento de conteúdos. Estes complexos processos requerem, a todo o momento, o emprego de estratégias que focam os espaços de informações organizacionais, proporcionando a identificação de novas competências. Deste modo, a adoção de um coeso conjunto de políticas para estes ambientes se torna necessário, assegurando que o esforço na elaboração de arquiteturas da informação organizacionais seja realizado, de forma coordenada e harmônica. 
A arquitetura da informação aplicada a ambientes organizacionais adquire, assim, novos matizes, pois não se trata tão somente de recuperar, organizar e apresentar a informação. Os espaços informacionais de uma organização são complexos e compreendem além de tarefas relacionadas ao ciclo informacional também questões relativas ao uso de metodologias e aplicação de políticas e de demais instrumentos normativos.

\section{REFERÊNCIAS}

ABELL, Angela; WINGAR, Lucy. The commercial connection: realizing the potential of information skills. Business Information Review. Londres, v. 2, n. 3, p. 172-181, 2005.

AGNER, Luis. Ergodesign e arquitetura da informação trabalhando com o usuário. Rio de Janeiro: Quartet, 2006.

BERBAUM, J. Études systémiques des actions: introduction à une méthodologie de recherché. Paris: PUF, 1982.

BRANDÃO, H. P.; BAHRY, C. P. Gestão por competências: métodos e técnicas para mapeamento de competências. Revista do Serviço Público, v. 56, n. 2, p. 179-194, 2005.

CAMARGO, L. S. A.; VIDOTTI, S. A. B. G. Arquitetura da informação para biblioteca digital personalizável. Encontro de Biblioteconomia: Revista eletrônica de Biblioteconomia. Ciência da Informação, Florianópolis, n. esp., p. 103-118, 1ㅇsem. 2006.

Disponível em: <http://www.periodicos.ufsc.br/index.php/eb/issue/view/103>. Acesso em: 06 jul. 2009.

CARABALLO PÉREZ, Yeter; RAMÍREZ CÉSPEDES, Zulia. El ciclo de vida de la información en la Web. Ciencias de la información, v. 38, n. 1-2, p. 31-40, abr./ago., 2007.

CAREER DIRECTIONS. Tech Directions, p. 28-30, ago. 2005.

CASAGRANDE, Nelson Granemann. Metodologia para modelagem de arquitetura da informação estratégica para pequenas empresas: uma aplicação no setor de turismo rural. Tese (Doutorado em Administração). Universidade Federal de Santa Catarina, Florianópolis, 2005.

CUNHA, Murilo Bastos da; CAVALCANTI. Cordélia Robalinho de Oviveira. Dicionário de Biblioteconomia e Arquivologia. Brasília: Briquet de Lemos, 2008.

GARRETT, Jesse James. A disciplina arquitetura da informação e o cargo de arquiteto, 2002. Disponível em: <http://jjg.net/ia/recon/pt-br.html>. Acesso em: 12 nov. 2006.

GIL, A. C. Gestão de pessoas: enfoque nos papéis profissionais. São Paulo: Atlas, 2001.

GUENTHER, Kim. Where have all the webmasters gone? Online, v. 29, n. 2, mar./abr. 2005. 
GUIMARÃES, et al.. Forecasting core competencies in an R\&D Environment. R\&D Management, v.31, n. 3, p. 249-255, jul. 2001.

HENDERSON, R.; WILSON T.; SHIMBO M. Dating example for information architecture. CHI 2003, p. 1022-1023, abr. 2006.

LOPES, Ilza Leite. Estratégia de busca na recuperação da Informação: revisão da literatura. Ciência da Informação, v. 31, n. 2, p. 60-71, maio/ago., 2004.

MORROGH, Earl. Information architecture: An Emerging $21^{\text {st }}$ Century Profession. Nova jersey: Prentice Hall, 2002.

MORVILLE, Peter. Ambient findability. Sebastopol: O’Reilly, 2005.

PEÓN ESPANTOSO, José Juan. A arquitetura da informação na intranet dos sítios do EME. Dissertação (Mestrado em Ciência da Informação). Universidade de Brasília, Distrito Federal, 2001.

RAMOS, M. N. A pedagogia das competências: autonomia ou adaptação? São Paulo: Cortez, 2001.

ROTHWELL, W. J.; LINDHOLM, J. E. Competency identification, modeling and assessment in the USA. International Journal of Training and Development, Oxford, v. 3, n. 2, p. 90-105, jun.1999.

RUAS, R. et al. O conceito de competência de $A$ à $Z$ - análise e revisão nas publicações nacionais entre 2000 e 2004. In_ XXIX ENANPAD - Encontro Nacional de Pós-Graduação em Administração. Anais... Brasília: ENANPAD, 2005.

SÁNCHEZ BUSTAMANTE, Antonio Montes de Coca. Arquitectura de información y usabilidad: nociones básicas para los profesionales de la información. Revista Cubana de Los Profesionales de La Información y Salud. Havana, ACIMED, v. 12, n. 6, nov. 2004. Disponível em: <http://www.bvs.sld.cu/revistas/aci/vol12 6 04/aci04604.htm>. Acesso em: 05 jan. 2007.

TRASATTI, Sidney Roberto; COSTA, Maria Inês. Administração de recursos humanos por competências: a gestão do novo contrato entre pessoas e empresas do terceiro milênio. In (org.) Gestão de RH por competências e a empregabilidade. Agnaldo Néri (org.). São Paulo: Papirus, p. 13-21, 2005.

VELASCO MARTÍN, Javier. Herramientas de arquitectura de información para el diseño de bibliotecas digitales universitarias. Biblioteca Universitária Nueva Época, v. 8, n. 1, p. 12-20, jan./jun. 2005.

WURMAN, R. S. Ansiedade de Informação 2. São Paulo: Cultura, 2001. 


\section{Notas}

\footnotetext{
${ }^{\text {i }}$ Formou-se arquiteto em 1959 e é mestre em arquitetura pela Universidade da Pensilvânia. Doutor honorário pela Universidade da Filadélfia (1994) e incluído em 1997 e 1999 pela revista Upside em lista de personalidades mais influentes dos Estados Unidos nas áreas de tecnologia, finanças, comunicações e governo.

ii Disponível em: <http;//www.asis.org>. Acesso em: 21 jun. 2006.

iii Grupo de interesse específico.

${ }^{\text {iv }}$ Arquitetura da Informação para o ambiente web.

${ }^{\mathrm{v}}$ Tecnologia da Informação.

vi Documento eletrônico.

vii Sociedade Americana para a Ciência da Informação e Tecnologia. Disponível em: < http://www.asis.org>. Acesso em: 23 fev. 2007 .

viii Estruturas.

${ }^{\text {ix }}$ Instituto para Arquitetura da Informação. Disponível em : <http://iainstitute.org/pg/competency_survey_2004.php>. Acesso em: 09 jan. 2007.

${ }^{\mathrm{x}}$ Instituto para a Arquitetura da Informação. Fonte: Disponível em:

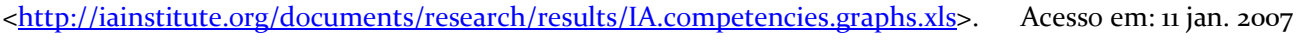

${ }^{x i}$ Estruturas modelo.

xii Melhores disponíveis.
} 